\title{
The Properties of Brown Marine Algae Sargassum turbinarioides and Sargassum ilicifolium Collected From Yogyakarta, Indonesia
}

\author{
Rahma Artemisia ${ }^{1,4}$, Erna Prawita Setyowati ${ }^{2}$, Ronny Martien $^{3}$ and Akhmad Kharis Nugroho ${ }^{3 *}$
}

1. Department of Pharmacy, Program Study of Pharmacy, Stikes Madani Yogyakarta, JL Wonosari Km. 10, Karanggayam, Piyungan, Bantul, Yogyakarta, Indonesia 55792

2. Department of Pharmaceutical Biology, Faculty of Pharmacy, Universitas Gadjah Mada, Sekip Utara, Yogyakarta, Indonesia 55281

3. Department of Pharmaceutics, Faculty of Pharmacy, Universitas Gadjah Mada, Sekip Utara, Yogyakarta, Indonesia 55281

4. Doctoral Program in Pharmaceutical Science, Faculty of Pharmacy, Universitas Gadjah Mada, Sekip Utara, Yogyakarta, Indonesia 55281

\section{Info Article}

Submitted: 23-07-2018

Revised: $26-2-2019$

Accepted: $13-3-2019$

*Corresponding author Akhmad Kharis Nugroho

Email:

a.k.nugroho@ugm.ac.id

\section{ABSTRACT}

Brown marine algae are the prominent source of marine natural products having bioactive metabolites. Sargassum turbinarioides (ST) and Sargassum ilicifolium (SI) were dominated in Indonesia as brown marine algae that well known as a source of fucoidan. In this study, we investigated and identified the yield of aqueous crude and purified extracts using different extraction temperatures $\left(60^{\circ} \mathrm{C}, 70^{\circ} \mathrm{C}, 80^{\circ} \mathrm{C}, 90^{\circ} \mathrm{C}\right)$. The highest yield of $S$. turbinarioides crude extract (7.36\%) was obtained at temperatures $90^{\circ} \mathrm{C}$ and $80^{\circ} \mathrm{C}$ while the highest return of $S$. ilicifolium was $3.49 \%$ at $80^{\circ} \mathrm{C}$. Each of the extracts was screened using Thin Layer Chromatography (TLC), Fourier transforms infrared spectroscopy (FTIR) analysis and Nuclear Magnetic Resonance (NMR) spectroscopy. The FTIR spectrum of the $S$. turbinarioides (ST) and S. ilicifolium (SI) extract refer to the presence of ester sulfate groups through showing peaks at 1300 to $1200 \mathrm{~cm}^{-1}$ and 980 to $950 \mathrm{~cm}^{-1}$. The NMR analysis proposed that the main structure of extract is L-fucopyranose and presence of different type of fucose sulfate groups. The result indicated that $S$. turbinarioides (ST) and $S$ ilicifolium (SI) contained sulfate polysaccharide. This may be a potential basic for development of marine nutraceuticals.

Keywords: $S$ turbinarioides, $S$ ilicifolium, Fucoidan, FTIR spectroscopy, NMR spectroscopy

\section{INTRODUCTION}

Marine algae have been increasingly studied over the years in pharmaceutical science to discover bioactive compound to develop as medicine, nutraceutical product, cosmeceutical, functional, healthy food and to design of drug delivery system (Cunha and Grenha, 2016). Based on the exhibited photosynthetic, marine algae can be classified into three types, brown marine algae (Phaeophyta), green marine algae (Chlorophyta), and red marine algae (Phaeophyta) (Fleurence and Levine, 2016). Brown marine algae, largest and most complex types of algae in the world, usually have yellow-brown color. About 1800 species of brown marine algae were distributed from tropical ocean area to polar ocean area in the world (Indrawati et al., 2015). The Brown marine algae are the massive spread of a lot of Indonesian ocean.

Brown marine algae include the genera Sargassum sp., Turbinaria sp., and Padina sp., have a large number of biological compounds such as a polysaccharide (fucoidan), alginate, laminarin which account for $40-80 \%$ of the extract (Sinurat, et al., 2016). Content and structured fucoidan (polysaccharide) for water-soluble fucoidan from different source depend on species (Kusaykin, et al., 2008), habitat and season of harvesting (Sinurat, et al., 2016). Numerous reports showed that fucoidan from brown marine algae 
present a broad range of biological activities (Kusaykin, et al., 2008; Wijesinghe and Jeon, 2012) such as antithrombotic (Jolly and Iyer, 2015), antioxidant (Ponce, et al., 2003), immunomodulator (Raghavendran, et al., 2011), anticoagulant, antibacterial, anticancer, antiviral, antitumor (Senthilkumar, et al., 2013), gastro protector (Ahmed, et al., 2014).

The biological activities of fucoidan are usually reported to depend on the position and content of sulfate groups in the fucoidan backbones (Thuy, et al., 2015), molecular weight, the composition of monosaccharide type of sugar, glucuronic acid and fucose content (Ale, et al., 2011; Thuy, et al., 2015; Zhao, et al., 2008). The bioactivity of crude fucoidan was generated by the fucoidan branches and backbone structural especially of the sulfate group. It needs to elucidate the underlying factors of fucoidan activity (Ale, et al., 2011). Structural characteristics of fucoidan are likely dependent on the technique of extraction (Ponce, et al., 2003), species of marine algae, the season of harvesting, geographic location (Sinurat, et al., 2016), and maturity of marine algae (Zvyagintseva, et al., 1999). Fucoidan can be extracted and purified from brown marine algae with various multi-step processed by involving with hot water, dilute acid, dilute alkali, physical and enzymatic treatment. Many purification and fractionation steps using a large volume of solvents and long extraction times used to get purified fucoidan (Holtkamp, et al., 2009).

Many analytical techniques can be used to investigate and detect bioactive compounds from the extract. Thin-Layer Chromatography (TLC), Fourier Transform Infrared spectroscopy (FTIR) and Nuclear Magnetic Resonance (NMR) spectroscopy analysis could be used to identify compounds. FTIR is regarded as a potential tool for determining the molecules. There are no two samples have the same infrared (IR) spectrum. Fourier Transform Infrared spectroscopy (FTIR) studies revealed different characteristic peak values of a various chemical component in the extract. The FTIR was used to detect the typical functional groups (Ashokkumar and Ramaswamy, 2014). Nuclear Magnetic Resonance (NMR) spectroscopy was used to identify molecules in an extract, quantify functional groups, and detected impurities and minor components. NMR spectroscopy analysis can provide detailed sequence distribution, a composition of structural information, molecular weight and substitution pattern (Cheng dan Neiss, 2012). This research focused on investigating the properties of $S$. turbinarioides (ST) and $S$ ilicifolium (SI) collected from Gunung Kidul, Yogyakarta, Indonesia which has not been reported so far.

\section{MATERIAL AND METHODS Materials}

$S$ ilicifolium (SI) and $S$ turbinarioides (ST) were collected from Drini Beach, Gunungkidul, Yogyakarta, Indonesia in June 2017. The reference standards of fucoidan from Undaria pinnatifida were purchased from Sigma-Aldrich Chemical Co. Used solvents included aquades, ethanol, acetone, dietileter, methanol, and chloroform. All solutions used for analytical and extraction process were obtained from E. Merck (Darmstadt, Germany).

\section{Instrumentation}

Absorption band of crude extract was monitored by Fourier transform infrared (FTIR) spectroscopy (Nicolet iS10 Thermo Scientific, USA), Nuclear Magnetic Resonance (NMR) spectroscopy (JEOL 400MHz), centrifuge (HeraeusChrist GmbH, Osterode, Germany), volume pipette (Pyrex), micropipette 100-1000 $\mu \mathrm{L}$ (Thermo Scientific).

\section{Sample preparation}

S. ilicifolium (SI) and S. turbinarioides (ST) were collected in June 2017 from Drini beach, Gunungkidul, Yogyakarta, Indonesia. Samples were identified and authenticated by Taxonomy Laboratory of Biology Departement, Faculty of Biology, Universitas Gadjah Mada to determine the taxonomic position. Brown marine algae samples were cleaned of epiphytes to remove waste and necrotic parts. Samples were washed with fresh water and were dried in the sun for two days in an oven at a temperature $50^{\circ} \mathrm{C}$ for two days. The samples were cut into small pieces and then pulverized into fine powder in a mixer grinder in $40 \mathrm{~mm}$ mesh size. The dried powder sample was kept in a dried, clean, and sealed container well.

\section{Extraction procedure}

The extraction procedure was performed as described by Li, et al. (2006) with slight modification. Each of $S$. ilicifolium (SI) and $S$. turbinarioides (ST) (10g) were extracted with hot water $(1: 10 \mathrm{~g} / \mathrm{mL})$ with a variety of different temperatures of extraction such as $60,70,80$, and $90^{\circ} \mathrm{C}$ for one hour at room temperature. The obtained hot water extracts were filtered through 
Buchner vacuum. Each filtrate was centrifuged at $6000 \mathrm{rpm}$ for $10 \mathrm{~min}$. The supernatant was filtered by nylon cloth. Ethanol $96 \%$ was added to supernatant as far as consist of precipitation and produced double layer. The precipitate was filtered through with Buchner vacuum, washed with Ethanol 96\%, acetone, and diethyl ether. The yield was air dried at $40^{\circ} \mathrm{C}$ for $24 \mathrm{~h}$ and then pulverized into fine powder. The yield was calculated based on equation 1 .

Yield $(\%)=\frac{\text { Weigh of the extract }(\mathrm{g})}{\text { Weight of the dried biomass }(\mathrm{g})} \times 100$ (1)

\section{Purification of crude extract}

The dried of crude extract (1g) was dissolved in water $(40 \mathrm{~mL})$. The solution was mixed with $3 \mathrm{M} \mathrm{CaCl}_{2}(1.5 \mathrm{~mL})$. Ethanol $96 \%$ was added to the solution. The precipitate was filtered through Buchner funnel and vacuum pump, washed with acetone, and diethyl ether. The precipitate was dried at $40^{\circ} \mathrm{C}$ for $24 \mathrm{~h}$ to get a purified fucoidan (Li, et al., 2006).

\section{Thin-Layer Chromatography (TLC)}

The crude extract was hydrolyzed with 0.01M HCl for 60min (Pielesz and Biniaś, 2010). Samples were spotted on TLC plate by micropipette standardized for five times. TLC was performed on a silica gel aluminium plate (silica gel GF 254) to the fractionated active compound of the crude extract. The chloroform: methanol $(1: 1 \mathrm{v} / \mathrm{v})$ was the mobile phase. The separated spots were market, and the Rf value was calculated (Jolly and Iyer, 2015). The spot was visualized after spraying $\mathrm{H}_{2} \mathrm{SO}_{4}$ : methanol $(1: 1 \mathrm{v} / \mathrm{v})$ and heating until the formation of dark spot on TLC plate.

\section{FTIR spectroscopy analysis}

The qualitative investigation of the purified fucoidan was done by FTIR spectrophotometer (Nicolet iS10 Thermo Scientific, USA). The spectra were recorded between 4000 and $400 \mathrm{~cm}^{-1}$ wavenumber, and the trembling was marked as a graphic representation. FTIR spectrophotometer equipped with a deuterated triglycine sulfate (DTGS) detector and a $\mathrm{KBr} /$ germanium as the beam splitter, interfaced to a computer having Horizon MB software and Windows operating system, was used for FTIR acquisition for spectra. A little of $S$. turbinarioides (ST) and S. ilicifolium (SI) extract was positioned in contact with attenuated total reflectance (ATR). The ATR was carefully cleaned by tissue with acetone twice before filling in with next sample. These spectra were recorded as absorbance values at each data point.

\section{NMR spectroscopy analysis}

The dried of crude extract $(20 \mathrm{mg})$ was dissolved in $1.0 \mathrm{~mL}$ Deuterium Oxide $\left(\mathrm{D}_{2} \mathrm{O}\right) .{ }^{1} \mathrm{H}$ nuclear magnetic resonance was acquired on a JEOL $400 \mathrm{MHz}$ at $65^{\circ} \mathrm{C}$. The measurement of ${ }^{1} \mathrm{H}$ $\mathrm{NMR}$ in ppm relative to internal reference Deuterium Oxide $\left(\mathrm{D}_{2} \mathrm{O}\right)$ at $4.7 \mathrm{ppm}$ (Li et al., 2006; Sinurat et al., 2016b).

\section{RESULTS AND DISCUSSION Extraction of brown marine algae}

S. ilicifolium (SI) and S. turbinarioides (ST) were extracted with hot water $(1: 10)$ at $60,70,80$, and $90^{\circ} \mathrm{C}$ for one hour to get water soluble in polysaccharide (fucoidan). Centrifugation at 6000 rpm was done to separate supernatant and filtrate. Ethanol 96\% was added to the supernatant to make a precipitate of the polysaccharide. Ethanol $96 \%$, acetone, and diethyl ether were added to rinse the impurities that soluble in the extract. The yield of crude extract of various extraction temperature from Sturbinarioides (ST) and $S$ ilicifolium (SI) (Table I). In general, the value of the yield of the crude extract is higher in case of $S$. turbinarioides. The highest yield of $S$. turbinarioides crude extract was 7.36\%, obtained at temperature 90 and $80^{\circ} \mathrm{C}$. The highest yield of $S$. ilicifolium crude extract was $3.49 \%$, derived from temperature $80^{\circ} \mathrm{C}$.

Table I. The yield of crude extract of various extraction temperature from $S$. turbinarioides (ST) and S. ilicifolium (SI)

\begin{tabular}{ccc}
\hline \multirow{2}{*}{ Temperature $\left({ }^{\circ} \mathbf{C}\right)$} & \multicolumn{2}{c}{ Yield of crude extract (\%) } \\
\cline { 2 - 3 } & (ST) & (SI) \\
\hline 90 & 7.36 & 3.38 \\
80 & 7.36 & 3.49 \\
70 & 7.26 & 3.18 \\
60 & 6.00 & 2.89 \\
\hline
\end{tabular}

The temperature had an essential role in yield of extraction. Fucoidan content of the extract decreased with increasing temperature, while sulfate content decreased as the temperature increased. The polysaccharide molecules are relatively stable at $70-80^{\circ} \mathrm{C}$. Time extraction and high temperature caused depolymerization of polysaccharide into decreased solubility and free sugars (Sugiono, et al., 2014). Fucoidan usually 
exists in dry brown marine algae about 5-10\%, depending on the harvesting period, thallus part that is being used, and the species of algae (Cunha and Grenha, 2016). The result of extraction can be concluded that different brown marine algae species and different condition of extraction giving the different yield of extract.

\section{Purification of crude extract}

The dried crude extract was dissolved in distilled water. The solution was mixed with $\mathrm{CaCl}_{2}$ for the purification of crude extract and elimination of algin (Li, et al., 2006). Ethanol 96\% was added to the solution to make polysaccharide precipitation. Acetone and diethyl ether was washed to remove the impurities on the extract. The precipitate was dried at $40^{\circ} \mathrm{C}$ for $24 \mathrm{~h}$ to get a purified fucoidan. The highest yield powder of purified extract $S$. turbinarioides (ST) $84.61 \%$ at temperature $90^{\circ} \mathrm{C}$. The highest yield powder of purified extract S. ilicifolium (SI) $75.67 \%$ at temperature $80^{\circ} \mathrm{C}$.

\section{Thin-Layer Chromatography (TLC)}

Thin-Layer chromatography (TLC) is used to separate compound on the crude extract of $S$. turbinarioides (ST) and S. ilicifolium (SI) by the distribution between two phases (solid-liquid). The advantages of TLC are the ability of it to separate the compounds quickly as well as it is an inexpensive tool. Like-dissolves-like can be applied to separate molecule in the extract. The polar stationery can be attracted polar molecule more strongly. The polar solvent and nonpolar solvent were combined to use for mobile phase because the polysaccharide is the polar molecule.

The bands obtained showed the Rf value of crude extract of $S$. ilicifolium (SI) and crude extract of $S$. turbinarioides (ST) similar to the standard Rf value of fucoidan commercial (0.68). The spot was visualized by UV lamp and spray with $\mathrm{H}_{2} \mathrm{SO}_{4}$ : methanol $(1: 1 \mathrm{v} / \mathrm{v})$ to heating until formed dark spot on TLC plate. The dark spot is identified that monosaccharide on the extract. If the color of the spot and $\mathrm{Rf}$ value were the same, the extract and the commercial standard fucoidan have the same biological metabolites (Wang, et al., 2015).

\section{FTIR spectroscopy analysis}

The crude extract and purified extract obtained at various extraction temperatures were analyzed by FTIR to determine the specific absorption bands present in the recovered product. Fucoidan commercial was used as a standard. FTIR spectra showed that all the evaluated samples exhibited an absorption band that is typical of fucoidan. FTIR spectroscopy has widely used to evaluate the biological metabolites. FTIR spectroscopy is a sensitive, fast and non-destructive technique. Furthermore, the instrument is easy to use, and it does not consume reagents and solvents (Berthomieu and Hienerwadel, 2009; Rohman, et al., 2011).

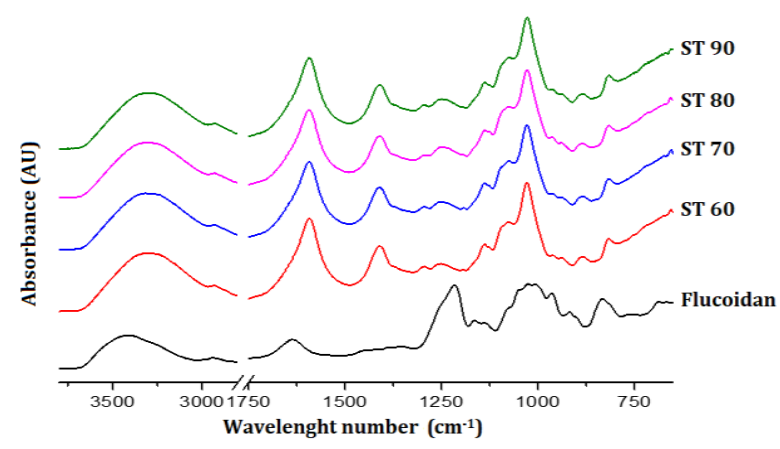

Figure 1. FTIR spectra of crude extract from $S$. turbinarioides (ST) from different extraction temperature and a commercial fucoidan from $U$. pinnatifida

Figure 1 exhibit FTIR spectra of $S$. turbinarioides (ST) crude extract obtained at extraction temperatures $90,80.70$ and $60^{\circ} \mathrm{C}$, and the standard fucoidan obtained from U. pinnatifida at frequency region $4000-400 \mathrm{~cm}^{-1}$. The crude extracts of various temperature extraction from $S$. turbinarioides (ST) showed that each sample has eight peaks in (ST) the area of wavelength number from $3316 \mathrm{~cm}^{-1}$ to $815 \mathrm{~cm}^{-1}$. Fucoidan commercial has a wavelength number from $3416 \mathrm{~cm}^{-1}$ to $833 \mathrm{~cm}^{-1}$. Taking in to account the spectra, it can be seen that ST $90,80,70$, and $60^{\circ} \mathrm{C}$ has the same peak with fucoidan standard. The absorption band at $1216-1255 \mathrm{~cm}^{-1}(\mathrm{~S}=0$ stretching) confirmed the presence of sulfate in the covered polysaccharides. The FTIR spectroscopy showed that the fucoidan bands were formed in the region of wave number 1500-1000 (Jolly dan Iyer, 2015). The sharp band at $840 \mathrm{~cm}^{-1}$ and the shoulder at $820 \mathrm{~cm}^{-1}$ (C-S-O) suggest a complex pattern of substitution at the $\mathrm{C}$ 4 position with other substitution at $\mathrm{C}-2$ or $\mathrm{C}-3$ at the equatorial position. The wavelength number $3415 \mathrm{~cm}^{-1}$ presence of a hydroxyl group (Lim, et al., 2002). Fucoidan is the complex group of polysaccharide which composed of L-fucose and sulfate ester groups (Pérez, et al., 2016). 
Table II. FTIR spectral peak values and functional groups obtained of $S$. turbinarioides (ST) and S. ilicifolium (SI)

\begin{tabular}{ccc}
\hline Extracts prepared & Peak values $\left.\mathbf{( c m}^{-1}\right)$ & Functional groups \\
\hline & 3315 & OH group \\
Sargassum turbinarioides & 1593 & CH bending \\
(ST) & 1240 & S=0 stretching \\
& 1255 & S=O stretching \\
& 1137 & C-O stretching \\
& 1027 & carbohydrate \\
& 939 & carbohydrate \\
Sargassum ilicifolium & 963 & carbohydrate \\
(SI) & 816 & C-S-O \\
\hline & 3404 & OH group \\
& 1323 & CH bending \\
& 1250 & S=0 stretching \\
& 1230 & S=O stretching \\
& 1137 & C-O stretching \\
& 1027 & carbohydrate \\
& 961 & carbohydrate \\
\end{tabular}

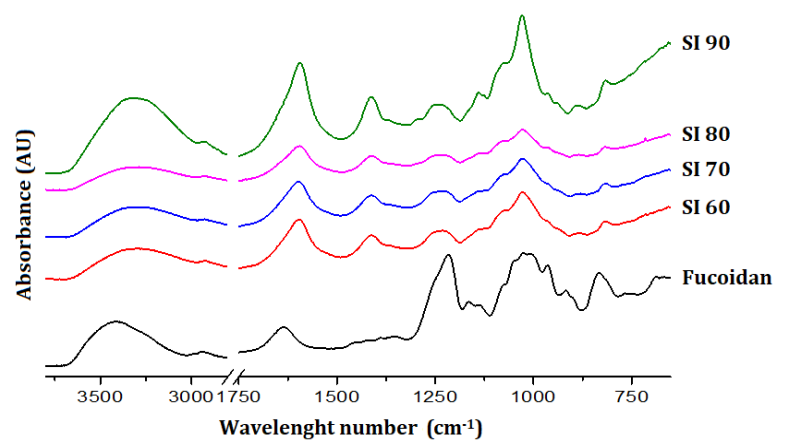

Figure 2. FTIR spectra of crude extract from $S$. ilicifolium (SI) from different extraction temperature and a commercial fucoidan from $U$. pinnatifida

The FTIR spectra (Figure 2) clearly show that all evaluated samples of crude extract of $S$. ilicifolius (SI) exhibited absorption bands. The fucoidan standard has eight peaks the same as the crude extract of $S$. ilicifolius (SI) temperature 70 and $60^{\circ} \mathrm{C}$. That was different from the crude extract of $S$. ilicifolius (SI) temperature 80 only have seven peaks and temperature $80^{\circ} \mathrm{C}$ only have six peaks. The absorption band at $1240-1255 \mathrm{~cm}^{-1}$ of all samples was drawn that $\mathrm{S}=0$ stretching confirmed the presence of sulfate in all the crude extract. The band at $815-840$ confirmed that

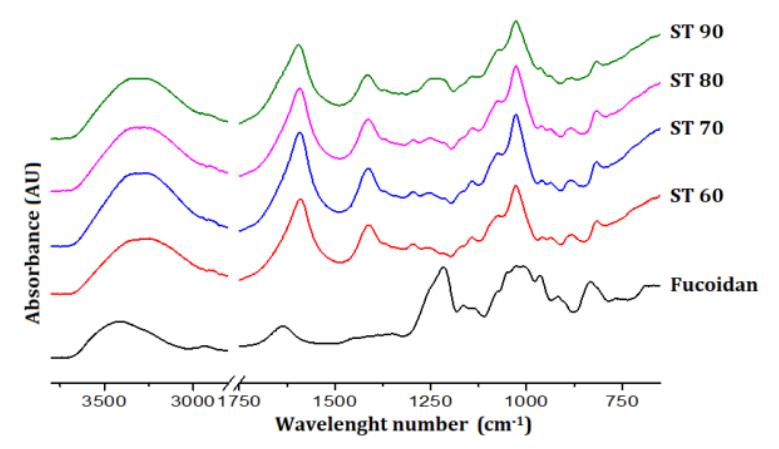

Figure 3. FTIR spectra of purified extract from $S$. turbinarioides (ST) from different extraction temperature and a commercial fucoidan from $U$. pinnatifida

suggest a complex pattern of substitution of C-S-O. The wavelength number around 3383 to $3420 \mathrm{~cm}^{-1}$ and near $2925 \mathrm{~cm}^{-1}$ due to vibration of $\mathrm{O}-\mathrm{H}$ and CH. FTIR spectral peak values and functional groups obtained of the crude extract of $S$. turbinarioides (ST) and crude extract of $S$. ilicifolium (SI) (Table II).

FTIR Analysis of purified extract from S. turbinarioides (ST) (Figure 3). The spectrum of FTIR analysis showed characteristic absorbance bands. All of the absorption bands from purified extract and fucoidan commercial has eight peaks. 


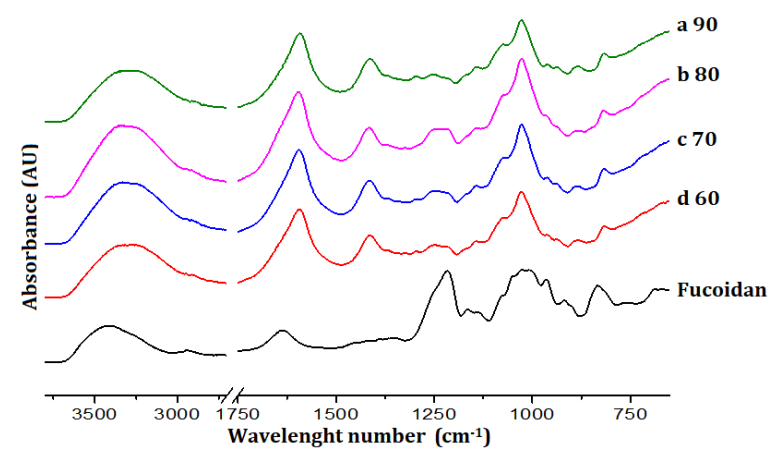

Figure 4. FTIR spectra of purified extract from S. ilicifolium (SI) from different extraction temperature and a commercial fucoidan from U. pinnatifida

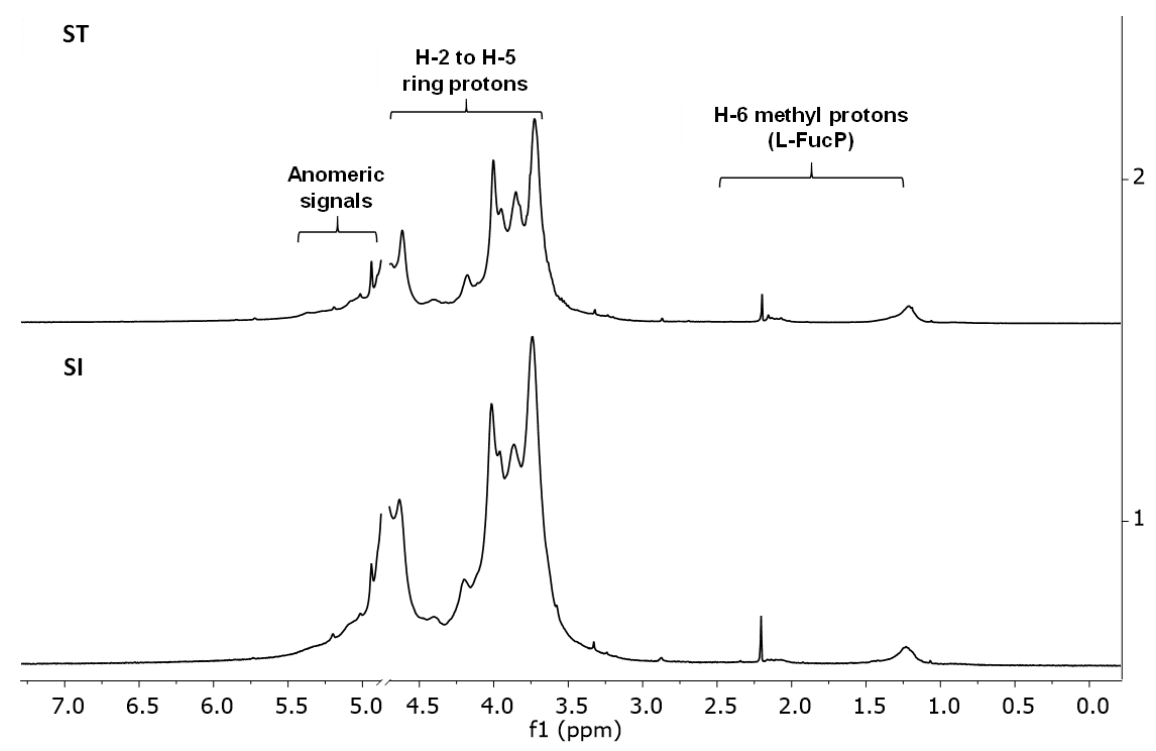

Figure 5. The stacked plot of $1 \mathrm{H}$ NMR spectra of crude extract from S. ilicifolium (SI) and crude extract from $S$. turbinarioides (ST)

The peaks at wavelength number near $1250 \mathrm{~cm}^{-1}$ are due to the presence of asymmetric $\mathrm{S}=0$ stretching vibration and symmetric $\mathrm{C}-\mathrm{O}$ vibration associated with the $\mathrm{CO}-\mathrm{SO}_{3}$ group (Manoj, et al., 2013). The wave near $820 \mathrm{~cm}^{-1}$ was present in fucoidan standard is due to more sulfation at equatorial at the position in C3 and C2 (Patankar, et al., 1993).

Absorption bands near $850 \mathrm{~cm}^{-1}$ were present in the crude extract of $S$. turbinarioides (ST) indicating that there is more sulfatation position at C4 (axial) (Pielesz and Biniaś, 2010). All species and fucoidan standard showed wavelength number around 3383 to $3420 \mathrm{~cm}^{-1}$ due to vibration of $\mathrm{O}-\mathrm{H}$ and $\mathrm{C}-\mathrm{H}$. Bands at $3400 \mathrm{~cm}^{-1}$ refer to $\mathrm{OH}$ stretching. The bands near $1620 \mathrm{~cm}^{-1}$ were due to C00- groups vibration (Pielesz and Biniaś, 2010).
The FTIR characterization of the purified extract of S. ilicifolius (SI) (Figure 4). All the samples of a purified extract of $S$. ilicifolius (SI) have eight peaks at temperature $80^{\circ} \mathrm{C}$ (Pielesz and Biniaś, 2010). The FTIR bands in the region of 900$1200 \mathrm{~cm}^{-1}$ are characteristic of carbohydrates (Pielesz and Biniaś, 2010). Comparing the spectra of Fucoidan standard and $S$. turbinarioides (ST) showed that the sharp peak in both compound at $820 \mathrm{~cm}^{-1}$ was related to the sulfate at the axial C-4 position, while only sulfate fucoidan showed at $833 \mathrm{~cm}^{-1}$ corresponds to sulfate that is substituted at C-6. The information on the molecular structure and chemical bond were obtained from FTIR spectra. Mainly, the intense and wide band that was formed in $3200-3550 \mathrm{~cm}^{-1}$ corresponded to the stretching vibration of the $\mathrm{OH}$ bond $(-\mathrm{OH}$ 
stretching) and associated with the presence of hydrogen bond. The wavelength number $1635 \mathrm{~cm}^{-1}$ is assigned to stretching vibration of $-\mathrm{C}=\mathrm{O}$ bond. Furthermore, the wavelength number $963 \mathrm{~cm}^{-1}$ and $833 \mathrm{~cm}^{-1}$ are attributed to the bending vibration of $=\mathrm{CH}$ and $=\mathrm{CH}_{2}$ bond (Chranioti, et al., 2016). Absorption at wavelength number $1259 \mathrm{~cm}^{-1}$ corresponds to $\mathrm{S}=0$ bonds. It was supported of a peak at $817 \mathrm{~cm}^{-1}$ has compared to sulfate at a central a position assumed that sulfate group at the position at $\mathrm{C}-2$ of fucose to sulfate fucose the same as fucoidan commercial at wavelength $833 \mathrm{~cm}^{-1}$ (Zvyagintseva, et al., 1999). The ester sulfate of FTIR spectrum is revealed from peak 1300 to $1200 \mathrm{~cm}^{-1}$. The ester sulfate at an equatorial was observed wavelength number from about 980 to $950 \mathrm{~cm}^{-1}$ (Halling, et al., 2015).

\section{Nuclear Magnetic Resonance (NMR) spectroscopy analysis}

The ${ }^{1} \mathrm{H}$ NMR spectrum of $S$. ilicifolium (SI) and $S$. turbinarioides (ST) (Figure 5). The ${ }^{1} \mathrm{H}$ NMR spectrum analysis was used to determine the anomeric configuration structure. The ${ }^{1} \mathrm{H}$ NMR analysis contained chemical shift from 5.0 to 5.8 ppm attributed to $\alpha$-linked-L-fucose and $\beta$-sugars (H1 $\beta$ ) of anomeric protons (H1 $\alpha$ ). The spectrum resonance characteristics of fucoidan with signals from ring protons ( $\mathrm{H}-2$ to $\mathrm{H}-5)$ at 3.5 to $4.5 \mathrm{ppm}$. It was confirmed the presence of different types of fucose sulfate groups with changes in monosaccharide patterns and glycosidic linkage positions. The chemical shift of ${ }^{1} \mathrm{H}$ NMR analysis between 1.1 to $2.1 \mathrm{ppm}$ confirmed H-6 methylated proton signals determined Lfucopyranose (L-FucP) (Alwarsamy et al., 2016; Lim et al., 2016).

\section{CONCLUSION}

The present study was demonstrated that the fucoidan could be successfully extracted from S. ilicifolium (SI) and S. turbinarioides (ST) by water extraction. The highest yield of crude extract from $S$. turbinarioides (ST) was 7.36\%, (90 and $80^{\circ} \mathrm{C}$ ) and crude extract from $S$. ilicifolium (SI) was $3.49 \%,\left(80^{\circ} \mathrm{C}\right)$. The crude extract or purified extract were contained phytochemical metabolites especially ester sulfate that revealed of FTIR spectrum from peak 1300 to $1200 \mathrm{~cm}^{-1}$. Fucoidan from brown seaweed is complex polysaccharide with complicated structures. The ${ }^{1} \mathrm{H}$ NMR spectrum analysis was used to determine the anomeric configuration structure. The ${ }^{1} \mathrm{H}$ NMR has determined L-fucopyranose as the primary structure of extract and presence of different type of fucose sulfate groups.

\section{ACKNOWLEDGMENT}

The first author would like to thank Syaiful Choiri for his technical support during the experiment. The author's thanks to Ministry of Research, Technology and Higher Education of the Republic of Indonesia and Beasiswa Unggulan Dosen Indonesia - Dalam Negeri (BUDI-DN) from Indonesia Endowment Fund for Education (LPDP) for sponsorship and financial support.

\section{REFERENCES}

Ahmed ABA., Adel M., Karimi P., Peidayesh M., 2014. Pharmaceutical, Cosmeceutical, and Traditional Applications of Marine Carbohydrates. Adv Food Nutr Res. 197220.

Ale MT, Maruyama H., Tamauchi H., Mikkelsen JD, and Meyer AS., 2011. Fucoidan from Sargassum sp. and Fucus vesiculosus reduces cell viability of lung carcinoma and melanoma cells in vitro and activates natural killer cells in mice in vivo. Int. J. Biol. Macromol. 49: 331-336.

Alwarsamy M., Gooneratne, R., dan Ravichandran, R., 2016. Effect of fucoidan from Turbinaria conoides on human lung adenocarcinoma epithelial (A549) cells. Carbohydr Polym. 152: 207-213.

Ashokkumar R. and Ramaswamy M., 2014. Phytochemical screening by FTIR spectroscopic analysis of leaf extracts of selected Indian Medicinal plants. International J Current Microbiology and Applied Sciences. 3: 395-406.

Berthomieu C. and Hienerwadel R., 2009. Fourier transform infrared (FTIR) spectroscopy. Photosynthesis Research. 101: 157-170.

Cheng HN. dan Neiss TG., 2012. Solution NMR Spectroscopy of Food Polysaccharides. Polymer Reviews. 52: 81-114.

Chranioti C., Chanioti S., Tzia C., 2016. Comparison of spray, freeze, and oven drying as a means of reducing bitter aftertaste of steviol glycosides (derived from Stevia rebaudiana Bertoni plant) - Evaluation of the final products. Food Chemistry. 190: 11511158.

Cunha L. and Grenha A., 2016. Sulfated Seaweed Polysaccharides as Multifunctional Materials in Drug Delivery Applications. Marine Drugs. 14: 42. 
Fleurence J. and Levine I., 2016. Seaweed in Health and Disease Prevention. Elsevier, Boston, MA. pp. 57-66.

Halling B., Vetvicka V., Blakemore W., 2015. Evaluation of The Immunomodulatory in vivo Activity of Laminaria Hyperborea Fucoidan Relative to Commercial $(1,3 / 1,6)$ B-D-Glucans from Yeast and Mushrooms. J Nutr Health. 2: 1-12.

Holtkamp AD., Kelly S., Ulber R., Lang S., 2009. Fucoidans and fucoidanases-focus on techniques for molecular structure elucidation and modification of marine polysaccharides. Appl Microbiol Biotechnol. 82: 1-11.

Indrawati R., Sukowijoyo H., Indriatmoko, Wijayanti RDE., Limantara L., 2015. Encapsulation of Brown Seaweed Pigment by Freeze Drying: Characterization and its Stability during Storage. Procedia Chem. 14: 353-360.

Jolly RR. and Iyer P., 2015. Isolation, Characterization, and Application of Fucoidan from Weeds. IJCRBP. 2: 212-216.

Kusaykin M., Bakunina I., Sova V., Ermakova S., Kuznetsova T., Besednova N., 2008. Structure, biological activity, and enzymatic transformation of fucoidans from the brown seaweeds. Biotechnol J. 3: 904-915.

Li B., Wei XJ., Sun J-L., Xu S-Y., 2006. Structural investigation of a fucoidan-containing a fucose-free core from the brown seaweed, Hizikia fusiforme. Carbohydrate Research. 341: 1135-1146.

Lim SN., Cheung PCK., Ooi VEC., Ang PO., 2002. Evaluation of Antioxidative Activity of Extracts from a Brown Seaweed, Sargassum siliquastrum. J Agric Food Chem. 50: 38623866.

Manoj SGM., Mahesh KPS., Vasanthi M., Anant A., 2013. Anticoagulant property of sulphated polysaccharides extracted from marine brown algae collected from Mandapam Island, India. Afr. J. Biotechnol. 12: 19371945.

Patankar MS., Oehninger S., Barnett T., Williams R.L., Clark G.F., 1993. A revised structure for fucoidan may explain some of its biological activities. J Biol Chem.. 268: 21770-21776.

Pérez MJ., Falqué E., Domínguez H., 2016. Antimicrobial Action of Compounds from Marine Seaweed. Marine Drugs. 14: 52.

Pielesz A. and Biniaś W., 2010. Cellulose acetate membrane electrophoresis and FTIR spectroscopy as methods of identifying a fucoidan in Fucus vesiculosus Linnaeus. Carbohydrate Research. 345: 2676-2682.

Ponce NMA., Pujol CA., Damonte EB., Flores ML., Stortz CA., 2003. Fucoidans from the brown seaweed Adenocystis utricularis: extraction methods, antiviral activity, and structural studies. Carbohydrate Research. 338: 153165.

Raghavendran HRB., Srinivasan P., Rekha S., 2011. Immunomodulatory activity of fucoidan against aspirin-induced gastric mucosal damage in rats. Int Immunopharmacol. 11: 157-163.

Rohman A., Che Man Y.B., Ismail A., Puziah H., 2011. FTIR spectroscopy combined with multivariate calibration for analysis of cod liver oil in binary mixture with corn oil. IFRJ. 18: 757-761.

Senthilkumar K., Manivasagan P., Venkatesan J., Kim S.K., 2013. Brown seaweed fucoidan: Biological activity and apoptosis, growth signaling mechanism in cancer. Int $\mathrm{J} \mathrm{Biol}$ Macromol. 60: 366-374.

Sinurat E., Peranginangin R., Saepudin E., 2016. Purification and Characterization of Fucoidan from the Brown Seaweed Sargassum binderi Sonder. Squalen Bulletin of Marine and Fisheries Postharvest and Biotechnology. 10: 79.

Sinurat, E., Saepudin, E., Peranginangin, R., dan Hudiyono, S., 2016b. Immunostimulatory activity of brown seaweed-derived fucoidans at different molecular weights and purity levels towards white spot syndrome virus (WSSV) in shrimp Litopenaeus vannamei. J.App.Pharm.Sci. 082-091.

Sugiono, Widjanarko SB., Soehono LA., 2014. Extraction Optimization by Response Surface Methodology and Characterization of Fucoidan from Brown Seaweed Sargassum polycystum. International Journal of ChemTech Research. 6: 195-205.

Thuy TTT., Ly BM., Van TTT., Van Quang N., Tu HC., Zheng Y., 2015. Anti-HIV activity of fucoidans from three brown seaweed species. Carbohydrate Polymers. 115: 122128.

Wang CY., Wu TC., Hsieh SL., Tsai YH., Yeh CW., Huang C.Y., 2015. Antioxidant activity and growth inhibition of human colon cancer cells by crude and purified fucoidan preparations extracted from Sargassum 
cristaefolium. Journal of Food and Drug Analysis. 23: 766-777.

Wijesinghe WAJP. dan Jeon, Y.J., 2012. Biological activities and potential industrial applications of fucose rich sulfated polysaccharides and fucoidans isolated from brown seaweeds: A review. Carbohydr Polym. 88: 13-20.

Zhao X., Xue CH., and Li BF., 2008. Study of antioxidant activities of sulfated polysaccharides from Laminaria japonica. $J$ Appl Phycol. 20: 431-436.

Zvyagintseva TN., Shevchenko NM., Popivnich IB., Isakov VV., Scobun AS., Sundukova EV., 1999. A new procedure for the separation of water-soluble polysaccharides from brown seaweeds. Carbohydrate Research, 322: 32-39.

A 